\title{
Independent Women Being Compassionate Towards Corporate Commitment
}

\author{
S. Rajeswari ${ }^{1 *}$, Seelaboyina Radha $^{2}$, K. Durga Kalyani $^{3}$, and Botla Mamatha ${ }^{4}$ \\ ${ }^{1}$ Department of Humanities \& Sciences, Gokaraju Rangaraju Institute of Engineering \& Technology, Hyderabad, India \\ ${ }^{2}$ Department of Computer Science Engineering, Geethanjali College of Engineering and Technology, Hyderabad, India \\ ${ }^{3}$ Department of Computer Science Engineering, Geethanjali College of Engineering and Technology, Hyderabad, India \\ ${ }^{4}$ Department of Computer Science Engineering, Geethanjali College of Engineering and Technology, Hyderabad, India
}

\begin{abstract}
Increasing in opportunities for women has changed the world which fills workspace culture gap in several sectors. Empowering women is one of the most pressing criteria for economic and social needs of a nation. The study focuses on contributions of women in corporate sector and sustaining active engagement in their personal life. Women disruptions to employment, stimulating deeper thinking with targeted business actions and self-management brings the most possible change in society. The findings show that women have developed considerable effect on the academic front whereas everincreasing work pressure is urging working women to spend less time for themselves. Women contributions in corporate sector is extremely important for prosperity and success of nations that make an incredible progress across the globe. The methods suggest that creating an envisioned process to improve gender parity in society by capitalizing human talents will make a better work place for women. This dearth of women in corporate boardrooms definitely steers the accountability. Results show that the presence of women in management positively with commitment and leadership affects significant untapped source of executive talent leading the way in decision and policy making.
\end{abstract}

\section{Introduction:}

Numerous sociologists set about from the theory that human behaviour is mostly aimed and driven by culture, such is the learned fashion caused by members of society. Morals, values and actions are culturally bound and socially imparted. From this point of view, gender roles are produced out of culture instead of biology. The status of women and their roles have been subject to effective changes over the past few millennia. From equal status with men of ancient periods through the minimal points of the medieval period, to the advocacy of equal rights by large number of reformers, the history of working women have been momentous. The growth of employment opportunities appears to be higher for women when compared with men. Large number of public bodies have become more vocal which supports the increased involvement and participation of women in high positions such as leaders, managers in corporate world. Status of working women can be defined as socio-economic freedom and equality enjoyed by them. They are recognised for their value at work place, engaged in a wide range of activities in addition to routine domestic work. Most of the women in urban areas contribute working in one form or the other. Though the cultural restrictions that women face are changing, they are not still free from men in formal economic participation. However, women today continue to face discrimination and other social challenges and are often victims of abuse and violent crime. The present study focuses on corporate women working in a wider perspective and their representation as a leader and responsible performer having work-life balance, taking productive decisions and making constructive policies, contributing for the growth of a nation.

\section{Literature Review}

Many studies have explored to identify women leaders and challenges faced in corporate sector. Their 'lived experiences' [1] such as harmonious relations, excluded opportunities to work in key roles, organisational support, etc., were highlighted. 
An ever increasing participation of women in all sectors brought change in development process is significant in social and domestic life. Women also entered board rooms of many corporate companies. Participation in economic activities brought identity in a wide range. Studies were made on gender diversity and its effect on corporate performance. 'The level of diversity' [2] differs from nation to nation focusing on married women [3] rather than unmarried working women with an emphasis on organised sector. Studies were also made on worklife conflict of full time employees due to long working hours. Several approaches were adopted by companies specifically to understand and analyse women's problems and finding solutions. This kind of study and analysis on women could bring social evolution through legal and economic route, treating them as individuals. Previous research produced mixed results which is empirically and theoretically complex to implement. The present study is an endeavour to a wider perspective of female representation focused on independent women towards corporate commitment.

\section{Methodologies}

This paper focuses on corporate working women and their commitment towards work. The approach is to examine work-life balance, upliftment of social and economic conditions in the society. The study is based on extensive review of literature and working women challenges in handling family and work.

\subsection{Women-work life balance}

Achievement of women in the intellectual field and increase of higher education has raised job prospects for women that resulted in move from home maker to thriving professional women. They are breaking the boundaries playing multiple roles with remarkable progress in all walks of life making noteworthy mark in their respective fields. In this cut-throat competitive world, the company's objectives and expectations from employees are changing increasingly. In order to meet employer's demand in the market, the employees have to extend themselves and are concerned more on their work that creates work-life imbalance. Striking balance between professional-life and personal-life is one of the most challenging tasks faced by working women. Majority of working women take care of their family members and managing the house. The conflict arises when they are keen in justifying both the roles efficiently. The most challenging task is striking balance between personal life and professional life. The factors that effect family among working women are 'harmony' [4] at home and work place. The nature of work, organisation support, skills required in their respective profession along with family expectations may also have impact on working women. Availability of baby care facility, flexibility to attend 'emergencies' [5] at home and possible work from home could be considered to have work-life balance for corporate working women. Independent variables like marital status, age and experience may influence working women. 'Reduced work stress and absenteeism, better motivation' [6] initiatives benefit work-life balance. Factors like talent identification, engagement and retention and increased job role autonomy support work-life balance. Most of the working women prefer supportive spouse and family as well as flexible timings and good ambiance to work at office. They are the primary caretakers for their children and elders of the family in most of the countries. Developing and setting guidelines of work-life balance policies, mentoring women are important for a sustained career growth towards management.

\subsection{Leadership and responsibility}

In today's world women became a flag bearer of society. Women leaders are diverse in terms of contribution to social welfare, education, politics, technology and many more. They look for work as income opportunities and as a career to fulfil their professional ambitions. Family support and background play a vital role to accomplish independence and is critical for working women experiencing great work pressure to prove themselves facing challenges. Organisational terms need to be sensitive of these issues and should appreciate their capabilities and talents. Women prefer interactive style to be successful in business and develop management styles that are more comfortable where reporting is easy for all sort of employees. The 'ability to influence' [7] a group towards achievement of vision and set of goals as a leader gain respect in business world.

Women leaders work on managerial culture to succeed with 'classical settings' [8] and routine activities.

Some of the strengths of women leaders may include

a. Being more empathetic, understanding and compassionate

b. Commitment and dedication towards work being loyal to their respective companies

c. Better crisis manager

d. Good at multitasking

e. Being strong communicators

f. Focus on teamwork

g. Work more holistically

h. Flexible and agile

Good ambiance and healthy environment at work place and happier families yields 'increased balance' 
[9] by women leaders. Significant characteristic traits of corporate women shape successful leaders of a nation. Thus, number of companies are enhancing women representation in workforce.

\subsection{A better financial performer}

The optimal use of talents of corporate women boost firm performance. In today's business world, leaders need to act with 'courage and commitment' [10]. Directors in corporate boards provide a valid form of legitimacy in potential employees symbolising career opportunities to 'potential recruitments' [11]. Such recruits show a better governance with positive repercussions on performance. In the aspect of entrepreneurship women contribute to improve employment, creates wealth and innovative economies that adds value to their profession. They hold high managerial positions representing independent workers. The positions are based on their level of work experience and education. They tend to make innovative, interactive and effective communication that results change in business structure. This provides competitive edge and helps to face different economic crisis. The increased trend of corporate women on boards is a distinct trend in business community. Various skill sets, personalities and values lead to adoption of different methods for leadership styles and decision making that have a significant implications for operations and function of an organisation.

\subsection{Decision and policy-making}

Opportunities to develop decision making skills and improve leadership capacities must be encouraged from childhood. Parents need to provide quality education and respect their daughters along with their sons and treat them equally. Educational institutions also need to address decision making and leadership cultures and adapt these practices in academic curriculums. At this point senior positions should hire women who act as role models and mentors supporting young generation establishing women's networks. Reservations for women enhance women's ability to participate actively in policy making. They have strong impact on women to represent themselves in various sectors. Participation in decision making strengthens democracy achieving goals of sustainable development. It is needed to identify and implement the appropriate measures that would redress underrepresentation of working women in decisionmaking through elimination of discriminatory practices by introducing positive action plans and programs. Women are considered as an undervalued resource at workforce which has been omitted from decision-making functions within business organizations. Corporate women deal effectively and in a well organised way with various points of leadership styles and strategies. From this perspective, such women can boost consciousness in corporate companies and build empathy within the workforce, constructing positive environment gaining the faith of external stakeholders. All necessary measures to achieve equal representation of women in public and political life should be observed. Women representation and participation in decision -making enhances empowerment.

\subsection{Corporate performance}

The real impact of women on corporate performance focuses on women on boards and in key roles, stockholders using corporate returns and their efficiency and market value. The accountability can be set on market variables that encompasses a wider perspective. The essential link necessary for good performance providing the organisation useful information, channel for communication, obtaining commitment of support and 'value in legitimising' [12]. [11] Investigated administrative characteristics to govern the effect of women appointments. Women directors on boards provide eminent form of 'legitimacy' $[11,13]$ in view of potential employees and corporate women directors also represent career opportunities to imminent recruits. The performance of a firm effects by the influence on company's strategic decision-making and role of supervisor that represents shareholders who respond appropriately to accept threats. Women might boost team performance which consider a high range of perspectives resulting to better decisions. These finally leads to 'higher business value and business performance' $[13,14,15]$. But most of the women choose to opt out of professional career to look after their family. The inherent solution is to steer a working environment which could be compatible with family life that benefits all other employees too. All private and public sector policies need to aim at raising the profile of women in the workplace and on the board

\subsection{Women in software}

Global economy is strikingly depending on software. This became common for companies to carry out their activities that support their business. Organisations are structured to meet the present market demands adopting innovative technology. Leading software companies set up joint ventures and many entrepreneurs started software companies. With well-educated work force a nation could benefit from policies of socio-economic development through technology. The relative success rests on a wide variety of interventions by the state and central governments and welfare provisions. However, retention and advancement seems to be a 'significant challenge' [16]. As such many companies are re-evaluating practices that 
may result in their company's growth and turnover with work-life balance.

McFarlane [17] argued that corporate women account a large part of the workforce and occupy a vital position in country's economy, IT profession needs women in its ranks as it could represent corporate women who carry out the work more strongly by a perceived behavioural control. The findings fit across position, income, educational qualification and self-efficacy. Proportional presence of corporate women in top positions where decision-making happens will go a long way making working environment conducive to women's needs. But some women may give up the chance of receiving higher paying jobs as they prefer not to relocate. This is because of social and cultural bias that women have themselves and by society in general. The key factors are that women act as mother, wife and also as a caretaker of their families during the peak periods of professional and academic careers. Here, structural factors of industry play a vital role to set their goals. Excited programs like women's Day celebrations raise awareness of developers in technology sharing the shortfall of women in technology sector.

\subsection{Women and society}

Upliftment of economic and social status of women is very important for women empowerment. Working women are quite essential for the development of society. This can be achieved by acquiring independent sources of income for women that generates self-esteem with improved conditions at all levels of their respective communities. The conflict among full-time employees may happen with long working hours, work-loads, organisations not supporting appropriate parenting. A better understanding of work-place dynamics for corporate women especially need to be checked by corporate companies. Elevating status of working women is often the greatest untapped resource of a community. It is the powerful and an effective process to promote international development. Socially and economically women are participating in more remarkable ways. Laws have been passed with respect to violence against women, reformation of family law and other ill-mannered issues. Such laws must be enforced and implemented in a more effective way. All women should be aware of their rights. Economic well-being of women yields to that favour working women's development. Economic opportunities help women empowerment and social development.

\section{Results}

The results are significant in the current context balanced administrative structures of corporate sectors where the graph of active female presence increases that leads to economic growth of a nation. The findings also suggest that women in key decision making bodies may perhaps perform more effectively than a strict economic perspectives of a company. It was also found during the study that as far as the administrative skills and leadership styles are involved usually men prefer women to act like men, and most of the men are not comfortable and feel convenient working for a woman leader. In fact, women prefer an interactive working style whereas men prefer a controlled and command style. To be a successful professional in business, women develop interactive managing styles that make the method more comfortable for men to report or work with a female manager. In spite of the fact that literacy alone is not sufficient to overcome the prevailing levels of discrimination, but one cannot discard its implicit for women's empowerment. Yet, the preferences of men and women still vary with respect to higher education. Lower literacy rate has an adverse effect on awareness of women in regard to their health needs. This may prevent the possibility of their admittance to services accessible for their well-being. This caused mainly due to additional responsibilities upon girls. It is broadly admitted that growth in the quality of women's education shall bring about gender advancement to a certain extent. Thus, women education had always been given preference. Nowadays, most of the women do not experience obstacles to access higher education, further the rise in their quality of education has been significant in recent years.

\section{Conclusion}

Gender discrimination is well identified with regard to women's advancement at workplace. The complication arises with the organization that do not see it as a strategic step on company's performance. Thus, an appropriate plan is essential towards making an organization gender diverse, as there would be strategic administration for a company's development and accomplishments in all other aspects. Working women contribute to the economy of a nation in one form or the other. However, working women employees opine, work-life balance was measured as not only a source of anguish but also the major 'source of dissatisfaction' [18]. The balance could be difficult to attain for full time women corporates irrespective of their work schedules ' especially for those with children' [19] . Thus, financial independence for an individual is essential. Such independence for women gives more respect in society. It also enhances reputation and begets more independence and freedom in the society. Corporate women feel self-empowered and helps them to have their own dignity in society. Women need to observe their corporate culture and support ethical behaviour before determining and 
deciding themselves to become a whistle blower. Consistent themes appear from both social and economic approaches. It is vital to appreciate the factors that promote and impede working women's gift to economic and business leadership.

\section{References}

1. Cho, Y., Park, J., Ju, B., Han, S., Moon, H, Park, S., Joo, A., Park, E., Human Resource Development Quarterly, 27, 461 (2016).

2. Carrasco G, A., J. L Briones, C de Buen G. Diversidad, Revista AECA, 76, 48 (2006)

3. Karl, M., Women in Action, 1, 8 (2009)

4. H. S. Sandhu, R. Mehta, Journal of Advances in Management Research, 3, 68, (2006)

5. N. Doble, M.V. Supriya, Management, 5, 331 (2010)

6. Byrne.U, Business Information Review, 22, (2005)

7. Robbins, P., Judge, T, Parker, D., Essentials of Organizational Behaviour, Upper Saddle River, (NJ: Pearson Prentice Hall, 9, 2008)

8. Budrina, I, Review of International Comparative Management, 13, 849, 2012.

9. McMillan, L., International Review, 1, 1, (2012)

10. Wittenberg-Cox, A., Alison, M., Why Women Mean Business: Understanding the Emergence of our Next Economic Revolution. (Hoboken: John Wiley \& Sons, 2008)

11. Hillman, A.J., Shropshire, C., Cannella, A.A., Academy of Management Journal, 50, 941, (2007)

12. Pfeffer, J., Salancik, G. R., The external control of organizations: A resource dependence perspective. (Stanford, CA: Stanford Business Books, 1978)

13. Singh, V., Vinnicombe, S., Corporate Governance, 12, 479, (2004)

14. Burgess, Z., \& Tharenou, P., Journal of Business Ethics, 37, 39 (2002)

15. Carter, D. A., Simkins, B. J., Simpson, W. G., The Financial Review, 38, 44-53, (2003)

16. Pfleeger S. L., Mertz, N., Communications of the ACM, 38, 63, (1995)

17. McFarlane JR, Management Services 3, (1990)

18. J. Hughes, Emerald Personnel Review, 36, 145 (2007)

19. I Hardoy, P Schone, British Journal of Industrial Relations, 44, 263, 2006. 